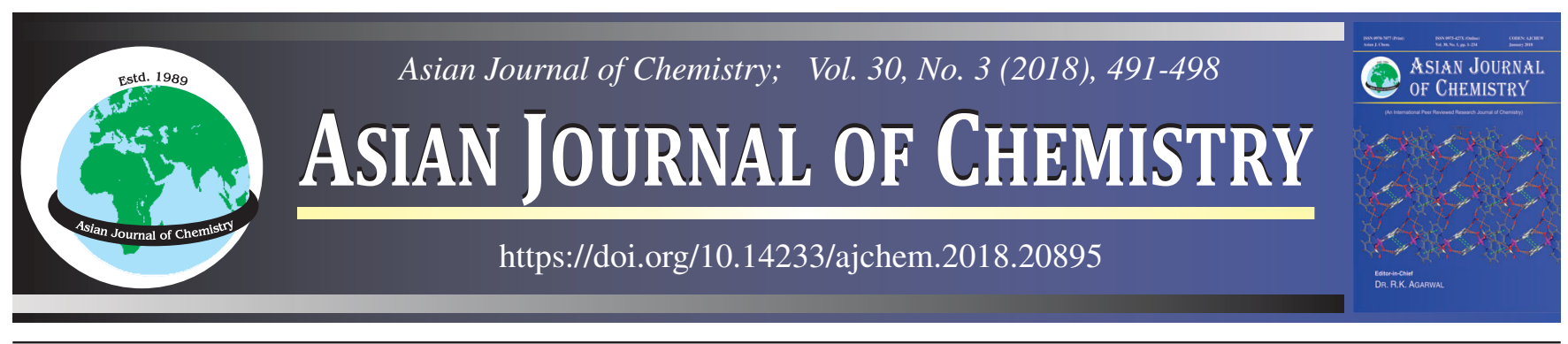

\title{
Immobilization of $\mathrm{Bi}_{2} \mathrm{O}_{3}$ Particles on Activated Carbon Fiber and Its Photodegradation Performance for Pollutant Dyes
}

Dinh Cung Tien Nguyen, Dong-Hyen Oh and Won-Chun OH*

Department of Advanced Materials Science \& Engineering, Hanseo University, Seosan-si, Chungnam 356-706, Republic of Korea

*Corresponding author: Tel: +82 41 6601337, E-mail: wc_oh@hanseo.ac.kr

Received: 30 June 2017;

Accepted: 29 September 2017;

Published online: 31 January 2018;

AJC-18730

A combination of activated carbon fiber and bismuth oxide $\left(\mathrm{Bi}_{2} \mathrm{O}_{3}\right)$ was prepared using a facile, one-step hydrothermal method. The resulting photocatalysts were characterized using X-ray diffraction, scanning electron microscopy, energy dispersive X-ray analysis, FT-IR spectra and BET method. UV-spectrophotometry was employed to measure the decrease in the concentration of rhodamine B, methylene blue trihydrate and reactive black B dyes in an aqueous solution after degradation with the photocatalysts under irradiation with visible light. The results contributes a new material to photocatalytic activity.

Keywords: Activated carbon fibers, Bismuth oxide, Photodegradation, Composite, Organic dyes.

\section{INTRODUCTION}

Bismuth oxide $\left(\mathrm{Bi}_{2} \mathrm{O}_{3}\right)$ offers many outstanding properties and has been extensively used in many different fields such as catalysis [1,2], energy materials [3,4], optoelectronics, optical coatings [5], etc. due to its high refractive index, large energy band gap (2-3.96 eV) and dielectric permittivity [6]. The material with bismuth ingredient has been found to be a potential candidate for catalysis that can degrade organic pollutants under UV-visible light [7-9]. Besides, the preparation of bismuth particles with different routes by using a chemical method such as pyrolysis of bismuth compound [10,11], hydrochemical method [12-15] and solid state reaction [16] also attracted much attention of scientists. Mallahi et al. [17] reported about the synthesis and characterization of bismuth oxide nanoparticles via sol-gel method. Oudghiri-Hassani et al. [6] reported the synthesis, characterization and photocatalytic activity of $\alpha$ $\mathrm{Bi}_{2} \mathrm{O}_{3}$ nano-particles.

On the other aspect, activated carbon fiber (ACF) is known as substrate source for synthetic nanomaterials that have many different targets, using a variety of synthetic approaches and combined with many types of nanomaterials. This material source is identified as the good candidate for preparing nanocomposite materials due to its high porosity and surface adsorption reactivity $\left(1000 \mathrm{~m}^{2} / \mathrm{g}\right)$ as well as larger pore volume than granular activated carbon (GAC) [18-22]. With several outstanding properties and functional groups on its surface, activated carbon fiber (ACF) is promising to make a positive effect in the photocatalyst activity [23]. One of the highlights of this material source is no significant effect on its adsorptive capacity with the change of $\mathrm{pH}$ value and temperature [24]. Yao et al. [25] reported the immobilization of $\mathrm{TiO}_{2}$ nanoparticles on activated carbon fiber and its photodegradation performance for organic pollutants. Li et al. [26] reported the synergetic effect between adsorption and photodegradation on nanostructured $\mathrm{TiO}_{2} /$ activated carbon fiber felt porous composites for toluene removal. Nevertheless, the synthesis of $\mathrm{ACF}-\mathrm{Bi}_{2} \mathrm{O}_{3}$ composite using a facile method, such as the hydrothermal method, however, the subsequent use of the materials have not been demonstrated yet.

To this end, a combination of activated carbon fiber (ACF) and $\mathrm{Bi}_{2} \mathrm{O}_{3}$ was prepared using a facile, one-step hydrothermal method and were used in the photodegradation of model organic pollutants rhodamine $\mathrm{B}$, methylene blue trihydrate and reactive black B in an aqueous solution under visible light irradiation. The obtained solution was then transferred into an autoclave for the hydrothermal reaction. The structure and morphology of $\mathrm{Bi}\left(\mathrm{NO}_{3}\right)_{3} \cdot 5 \mathrm{H}_{2} \mathrm{O}-\mathrm{ACF}$ composites were characterized via $\mathrm{X}$-ray diffraction (XRD), scanning electron microscopy (SEM), energy dispersive X-ray (EDX) analysis and FT-IR spectra. The surface area of the surveys composites were determined by using the BET method.

\section{EXPERIMENTAL}

Activated carbon fiber (ACF) was obtained from Nantong Sutong Carbon Fiber Co. Ltd. (Jiangsu, China). Bismuth nitrate pentahydrate (98\%), rhodamine B and methylene blue trihydrate were purchased from Samchun Pure Chemicals Co. Ltd., Korea. Reactive black B was purchased from JAY Chemical Industries 
Ltd., India. Hydrochloric acid (35-37\%) and ethanol (95\%) were purchased from Duskan Pure Chemicals Co. Ltd., Korea. Sulfuric acid (98\%) was purchased from Daejung, Korea. All the chemicals were used without further purification and the double distilled water was used throughout the experiments.

$\mathrm{X}$-ray diffraction (Shimadzu XD-D1) was used to determine the crystallinity with monochromatic high-intensity $\mathrm{CuK}_{\alpha}$ radiation $(\lambda=1.5406 \AA)$. Scanning electron microscopy (JSM5600 ) was used to observe the surface and structure of the prepared composites. Elemental mapping over the desired region of prepared composite was detected using an energy dispersive X-ray (EDX) analysis attached to SEM. The Fourier Transform Infrared (FT-IR) spectrum was obtained by Nicolet 360 spectrometry. Nitrogen adsorption/desorption isotherms studies were prepared using a Micromeritics ASAP $2020 \mathrm{M}+\mathrm{C}$ operating at $77 \mathrm{~K}$ using the Brunauer-Emmett-Teller (BET) method to determine the surface area.

\section{Detection method}

Grinded activated carbon fiber (ACF): The activated carbon fiber (ACF) was finely grounded with ball mill grinder machine to make ACF powder. The achieved ACF powder was smoothed by sieve.

Acid treatment: A moderate amount of ACF powder was added into a mixture of nitric acid:sulfuric acid:distilled water with volume ratio 1:3:1, then stirred with magnetic stirring for $6 \mathrm{~h}$ without temperature. The product was washed with distilled water until $\mathrm{pH}$ become neutral. The ACF powder with acid treatment was obtained after drying in a vacuum at $100^{\circ} \mathrm{C}$ for $48 \mathrm{~h}$.

Synthesis of $\mathrm{Bi}\left(\mathrm{NO}_{3}\right)_{3} \cdot 5 \mathrm{H}_{2} \mathrm{O}$-ACF composite: Part A was obtained via ultrasonication of a certain amount of $\mathrm{Bi}\left(\mathrm{NO}_{3}\right)_{3}$. $5 \mathrm{H}_{2} \mathrm{O}$ powder in $100 \mathrm{~mL}$ distilled water for $30 \mathrm{~min}$ (Ultrasonic Processor, VCX 750, 500 Watt, Korea, Power 500 Watt, frequency $20 \mathrm{KHz}$, Amplitude 50\%, low intensity). Vigorous stirring of the mixture of parts A and $1 \mathrm{~g}$ ACF powder was continued for $6 \mathrm{~h}$ at $70^{\circ} \mathrm{C}$. After a hydrothermal reaction occurred at $100^{\circ} \mathrm{C}$ for $18 \mathrm{~h}$, the product was washed with distilled water until $\mathrm{pH}$ become neutral. The $\mathrm{Bi}\left(\mathrm{NO}_{3}\right)_{3} \cdot 5 \mathrm{H}_{2} \mathrm{O}-\mathrm{ACF}$ composite was obtained after drying in a vacuum at $100^{\circ} \mathrm{C}$ for $48 \mathrm{~h}$. Similar samples were prepared corresponds to $0.01,0.02$, and $0.03 \mathrm{~mol}$ of $\mathrm{Bi}\left(\mathrm{NO}_{3}\right)_{3} \cdot 5 \mathrm{H}_{2} \mathrm{O}$ and labeled as ACF-A, ACF-B and ACF-C, respectively.

The typical photocatalytic test carried out at room temperature, the survey samples used in this study was found to be $0.05 \mathrm{~g}$, dissolved in $100 \mathrm{~mL}$ rhodamine B solution (200 ppm). Prior to irradiation, the above mixture solution was maintained in a dark box for $2 \mathrm{~h}$ to establish the adsorption/desorption equilibrium of organic dyes. The solution was then irradiated with visible light radiation $(\lambda \geq 420 \mathrm{~nm}$ ). The first sample was withdrawn at the end of dark adsorption period before switching on the light to determine the rhodamine B concentration in the solution after dark adsorption. The starting point $(t=0)$ of the reaction was defined as the point where concentration of rhodamine $\mathrm{B}$ solution was recorded as $\mathrm{c}_{0}$. Afterward, these samples were extracted from the solution mixtures in the reactor at regular intervals of 30,60, 90, 120, and $180 \mathrm{~min}$. The powder was dispersed using a centrifuge machine (10,000 ppm/15 min) before the analysis. The dye concentration in the solution was measured as a function of the irradiation time. The photodegradation of methylene blue and reactive black B solution proceeded following a similar process.

A UV-spectrophotometer (Opizen POP, Korea) was used to analyze the photodegradation of the dye solutions in terms of the concentration (c). A spectrophotometric analysis was performed on each sample of the dye solutions at regular time intervals to obtain the absorbance spectrum. The spectral range was investigated at $\lambda_{\max }=554,665$ and $591 \mathrm{~nm}$, respectively, for rhodamine $\mathrm{B}$, methylene blue and reactive black B by using a calibration curve since no reaction occurred with the absorption of products at these wavelengths (Table-1). The degradation capacity ( $\eta \%)$ was calculated as:

$$
\eta(\%)=\frac{1-\mathrm{c}}{\mathrm{c}_{\mathrm{o}}} \times 100
$$

The photodegradation of organic dyes was also observed for rhodamine B, methylene blue and reactive black B with (a) ACF-A, (b) ACF-B, and (c) ACF-C, following the same procedure as mentioned above.

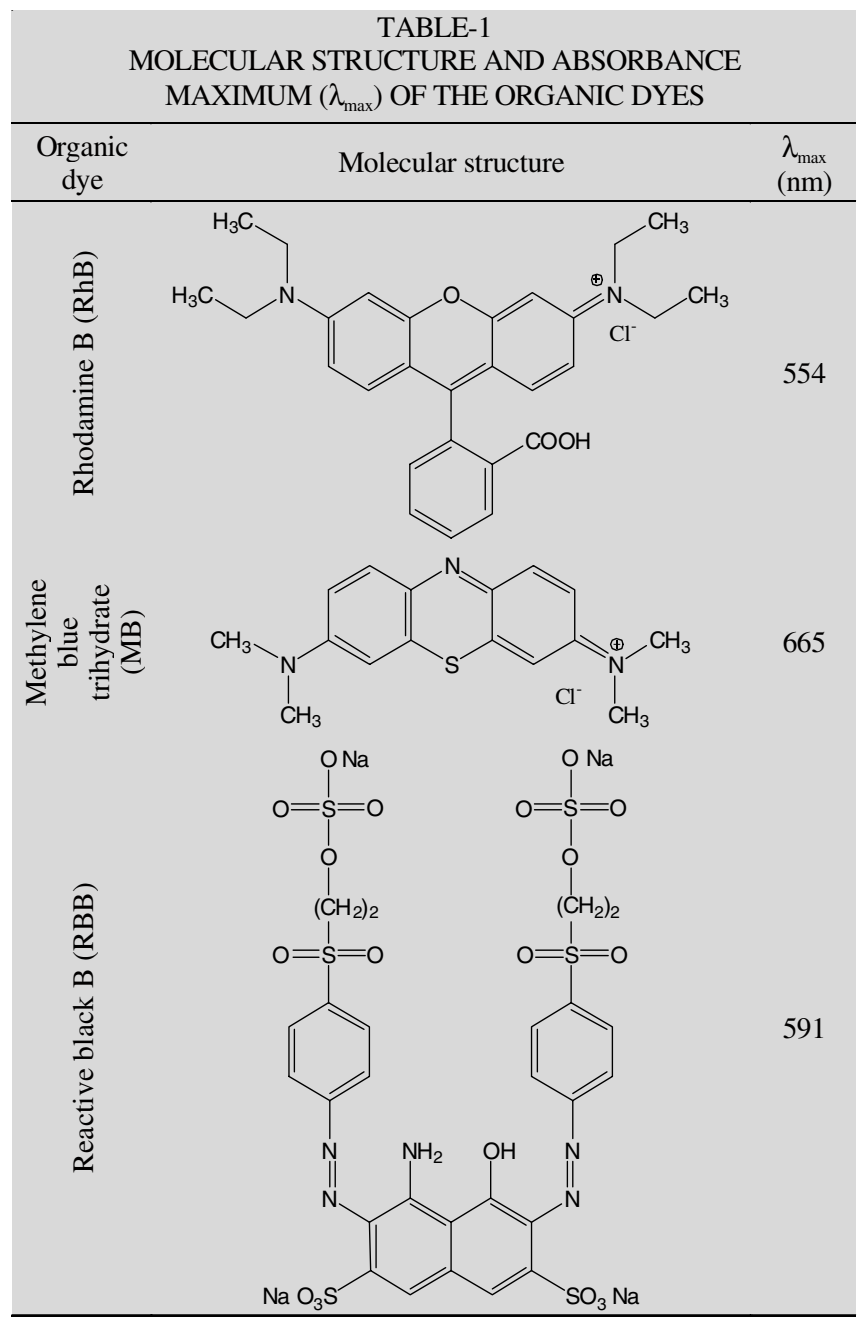

\section{RESULTS AND DISCUSSION}

The XRD patterns (Fig. 1) of all the samples shows three main diffraction peaks (120), (200) and (121) with the JCPDS file \#41-1449, which confirms the presence of monoclinic 


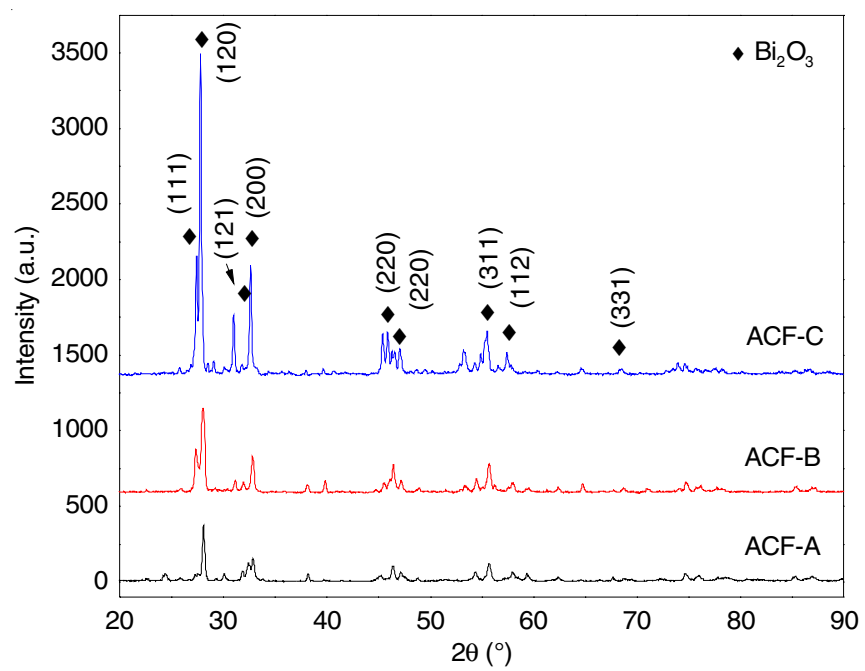

Fig. 1. XRD patterns of the ACF-A, ACF-B and ACF-C composites

$\mathrm{Bi}_{2} \mathrm{O}_{3}[6,27]$. All the diffraction peaks are clear and the purity of the nanocomposites was confirmed as no other unexpected peaks found. As there was an increased mole ratio of $\mathrm{Bi}\left(\mathrm{NO}_{3}\right)_{3} \cdot 5 \mathrm{H}_{2} \mathrm{O}$, the diffraction peaks of $\mathrm{Bi}_{2} \mathrm{O}_{3}$ was higher and more clearly. The obtained results showed that the prepared composites were almost perfect, with single phase, high crystallinity and purity.

Fig. 2 shows the SEM results of loaded activated carbon fiber $(\mathrm{ACF})$ and the different mole ratios of $\mathrm{Bi}\left(\mathrm{NO}_{3}\right)_{3} \cdot 5 \mathrm{H}_{2} \mathrm{O}$. According to Fig. 2(a-f), $\mathrm{Bi}_{2} \mathrm{O}_{3}$ particles with the variety of shapes were successfully covered on the ACF surface. Fig. 2(a-b) exhibited the shape state of $0.01 \mathrm{~mol}$ of $\mathrm{Bi}_{2} \mathrm{O}_{3}$ with $1 \mathrm{~g}$ ACF (ACF-A). As the result, $\mathrm{Bi}_{2} \mathrm{O}_{3}$ particles were presented as the block with disunion morphology. The average diameters of the particle sizes [Fig. 2(a-b)] were found to be around 150 and $220 \mu \mathrm{m}$. On the other hand, as the increased mol ratio of $\mathrm{Bi}\left(\mathrm{NO}_{3}\right)_{3} \cdot 5 \mathrm{H}_{2} \mathrm{O}$, the morphology of the samples was changed from spherical shape [Figs. 2(c-d)], ACF-B) to a disk-like shape with dispersant structure [Figs. 2(e-f), ACF-C]. Their particle sizes were approximately $250-600$ and $110-220 \mu \mathrm{m}$ for ACF$\mathrm{B}$, ACF-C samples, respectively. The pre-treatment of ACF with acid plays an important role in the morphology of the assynthesized composites. Besides, the uniformly immobilized with the difference shape of $\mathrm{Bi}_{2} \mathrm{O}_{3}$ particle on the surface of ACF substrate is promising to bring the variety of photodegradation results of the prepared samples.

The EDX microanalyses of ACF and $\mathrm{Bi}_{2} \mathrm{O}_{3}$ - ACF composites were also recorded as an example in order to obtain the information of the main elements in the prepared composites. According to Figs. 3(a-b), the ACF-C exhibited three kinds of peaks $\mathrm{C}, \mathrm{O}, \mathrm{Bi}$, and no other impurity was detected. This result means that a combination of $\mathrm{ACF}$ and $\mathrm{Bi}_{2} \mathrm{O}_{3}$ had successfully formed. In Fig. 3a, the strong peak of Bi appeared at $2.6 \mathrm{eV}$ and for oxygen at $0.56 \mathrm{eV}$ as an evidence of the presence of both elements in $\mathrm{Bi}_{2} \mathrm{O}_{3}$ composite. Table- 2 presents the mean amount of elements, which also suggested that the sample had three kinds major elements viz., $\mathrm{C}, \mathrm{O}$, and $\mathrm{Bi}$. In ACF case, the EDX was good with $88.28 \%$, and $11.72 \%$ corresponding to the $\mathrm{C}$ and $\mathrm{O}$ elements, without the presence of unexpected elements. Besides the presence of $\mathrm{C}, \mathrm{O}$, and $\mathrm{Bi}$ elements in ACF-A and ACF-B composites with major percent, the small amount impurity elements was detected (Table-2). Beyond the expectation, $\mathrm{ACF}-\mathrm{C}$ composite was absolutely pure which was rich in $\mathrm{Bi}(52.39 \%)$ but there is a disparity when compared to $\mathrm{C}$ and $\mathrm{O}$ elements (22.39 and $25.22 \%$, respectively). The BET analysis has proceeded and the results are presented in Table2. The BET surface area of ACF, ACF-A, ACF-B, ACF-C composites was $1125,950,920$ and $892 \mathrm{~m}^{2} / \mathrm{g}$, respectively. According to above results, it can seen that the surface area was reduced as a result of adding $\mathrm{Bi}_{2} \mathrm{O}_{3}$ particles in the ACF structure. With an increase in $\mathrm{Bi}\left(\mathrm{NO}_{3}\right)_{2}$ mole ratio, the more $\mathrm{Bi}_{2} \mathrm{O}_{3}$ particles anchored in the $\mathrm{ACF}$, which expected to have a high photocatalytic activity.
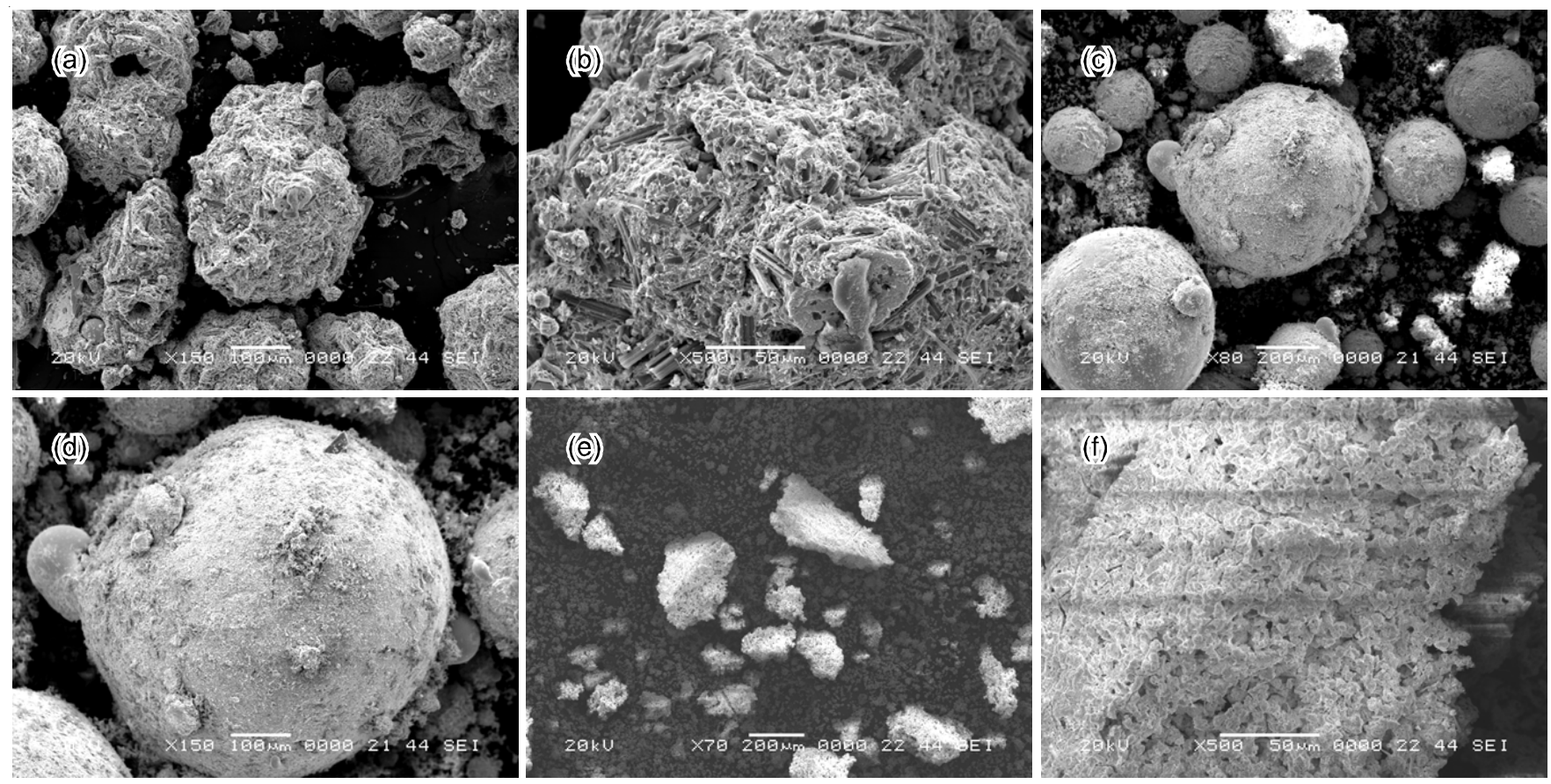

Fig. 2. SEM morphology of ACF-A (a and b), ACF-B (c and d) and ACF-C (e and f) composites 

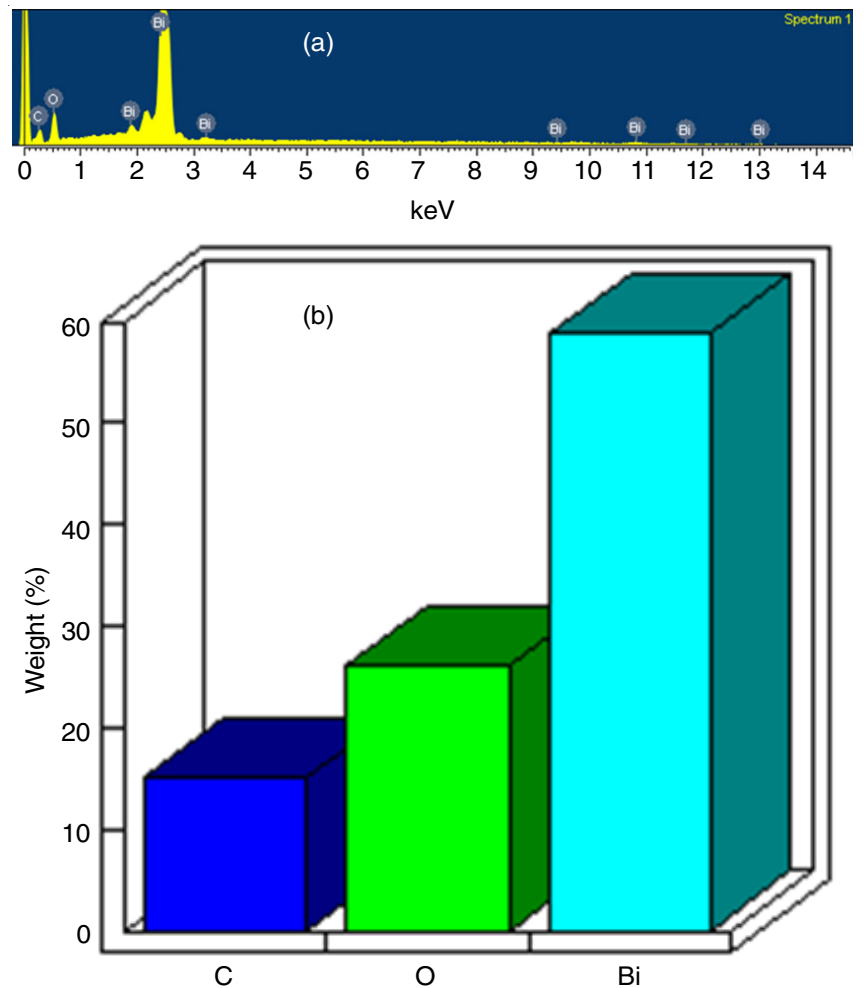

Fig. 3. EDX elemental microanalysis (a) and graphical representation of the quantitative analysis (b) of ACF-C composite

TABLE-2

ELEMENTAL MICROANALYSIS (wt \%) OF ACF AND $\mathrm{Bi}_{2} \mathrm{O}_{3}$-ACF COMPOSITES

\begin{tabular}{lccccc}
\hline Sample & $\mathrm{C}$ & $\mathrm{O}$ & $\mathrm{Bi}$ & Others & $\mathrm{S}_{\mathrm{BET}}\left(\mathrm{m}^{2} / \mathrm{g}\right)$ \\
\hline ACF & 88.28 & 11.72 & - & - & 1125 \\
ACF-A & 59.01 & 20.24 & 13.48 & 7.27 & 950 \\
ACF-B & 23.15 & 29.32 & 45.29 & 2.24 & 920 \\
ACF-C & 22.39 & 25.22 & 52.39 & - & 892 \\
\hline
\end{tabular}

According to the previous report, the FT-IR spectrum of actived carbon fiber shows a variety of peaks that can be attributed to oxygen-containing groups. The peaks centered at 3439, 1630 $\mathrm{cm}^{-1}$ assisted the -OH group stretching vibration bands, flexural vibration bands of -OH group, respectively. On the other hand, the peaks located at 2920 and $1122 \mathrm{~cm}^{-1}$ corresponded to the stretching vibration bands of the $-\mathrm{CH}_{2}$ group and in-plane flexural vibrations of the - $\mathrm{CH}$ group, respectively [28]. For comparison, FT-IR spectrum of $\mathrm{Bi}_{2} \mathrm{O}_{3}$-activated carbon fiber was surveyed. As the results in Fig. 4, the newly observed characteristic features at $590,1040 \mathrm{~cm}^{-1}$ were obtained as evidence proved that $\mathrm{Bi}_{2} \mathrm{O}_{3}$ particles covered the actived carbon fiber with the physical interaction, after the hydrothermal reaction. The disappearance of oxygen-containing groups of activated carbon fiber as well as the presence of new peaks corresponding to chemical bonds between $\mathrm{Bi}_{2} \mathrm{O}_{3}$ and activated carbon fiber $[29,30]$. The FT-IR spectrum and other results proved that the as-synthesized $\mathrm{Bi}_{2} \mathrm{O}_{3^{-}}$ activated carbon fiber was successfully synthesized.

Photodegradation: The organic dye degradation progressed in two stages. First, the adsorption/desorption equilibrium of organic dyes was established in a dark box for $2 \mathrm{~h}$. Then, the photocatalytic degradation experiment of the dye solutions was conducted under visible light irradiation with different irradiation times (from 0 to $180 \mathrm{~min}$ ).

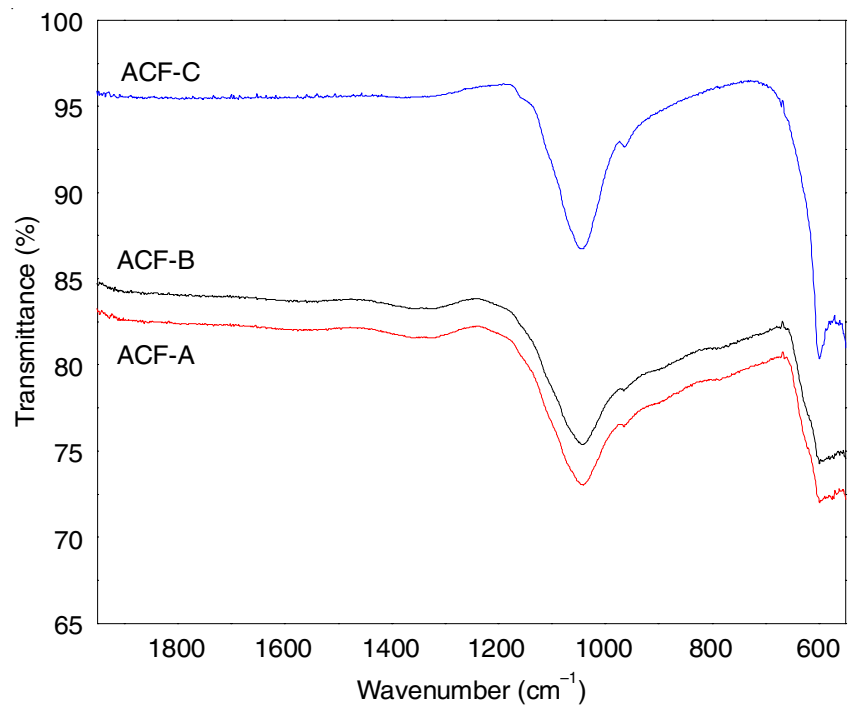

Fig. 4. FT-IR spectra of ACF-A, ACF-B and ACF-C composites

Degradation of rhodamine B: The degradation results of prepared samples with rhodamine B are shown in Fig. 5. Following the adsorption effect in a dark box for $2 \mathrm{~h}$, ACF-A achieved the highest rhodamine B removal with $11.26 \%$, while ACF-B and ACF-C were removed by around 5.43, and $8.45 \%$, respectively. For the photocatalytic degradation with $3 \mathrm{~h}$ under visible light irradiation, ACF-A still remained the best result with $25.47 \%$ rhodamine $\mathrm{B}$ removal, which is better than ACFB $(15.09 \%)$ and ACF-C (13.76\%). The above results showed that ACF-A is the best candidate for the rhodamine $\mathrm{B}$ removal than other dyes.

Degradation of methylene blue: The adsorption effect of ACF-A and ACF-B overtook the ACF-C with 11.78, 17.42, and $3.23 \%$ methylene blue removal, respectively (Fig. 6). Hence, ACF-B still kept the best percent of methylene blue removal with $25.44 \%$ after 180 min under visible light irradiation for the For the photocatalytic effect. Beisdes, ACF-A and ACF-C achieved the lower effect with 18.51 and $14.05 \%$, respectively.

Degradation of reactive black B: The photocatalytic degradation of reactive black $B$ in aqueous solution using prepared composites is shown in Fig. 7. With $9.51 \%$ reactive black B removal, ACF-C shows the best adsorption effect than ACF-A and ACF-B (2.82 \%, and $0.75 \%$, respectively (Fig. 7). Under the visible light, the absorption capacity of ACF-C continued to increase with the increase of irradiation time. The ACF-C composite showed the photodegradation results around $14.47 \%$ removal of reactive black B. Meanwhile, ACF-A and ACF-B composites showed photodegradation results around of 9.47 and $3.55 \%$, respectively, under the same experimental conditions.

Photocatalytic reactions with different photocatalysts were presented by the Langmuir-Hinshelwood model [31]. The photocatalytic degradation of dye containing different photocatalysts obeys the pseudo-first-order kinetics with respect to concentration of dye solution.

$$
-\mathrm{dc} / \mathrm{dt}=\mathrm{k}_{\mathrm{app}} \mathrm{c}
$$

Integration of eqn $\mathrm{I}$ (with the restriction of $\mathrm{c}=\mathrm{c}_{\mathrm{o}}$ at $\mathrm{t}=0$, where $c_{o}$ is the initial concentration in bulk solution after dark adsorption and $t$ is the reaction time) will lead to the following expected relation: 

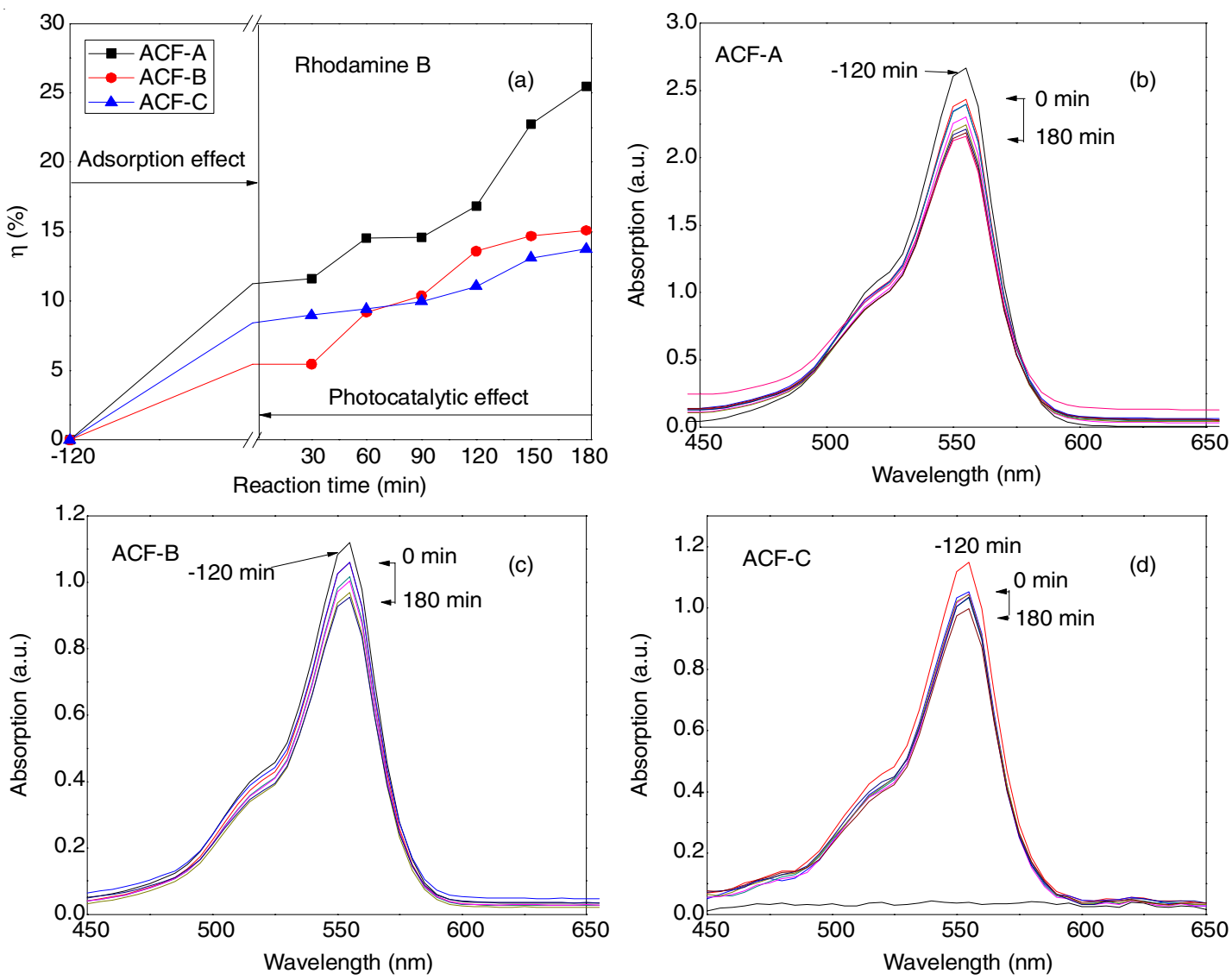

Fig. 5. Degradation of different composites with rhodamine $\mathrm{B}(\mathrm{RhB})$ under visible light irradiation. The amount of composites was $0.05 \mathrm{~g}$. The experiments were carried out at $100 \mathrm{~mL}$ of $5.0 \times 10^{-5} \mathrm{~mol} / \mathrm{L} \mathrm{mol} / \mathrm{L}$ dye concentration with neutral $\mathrm{pH}$
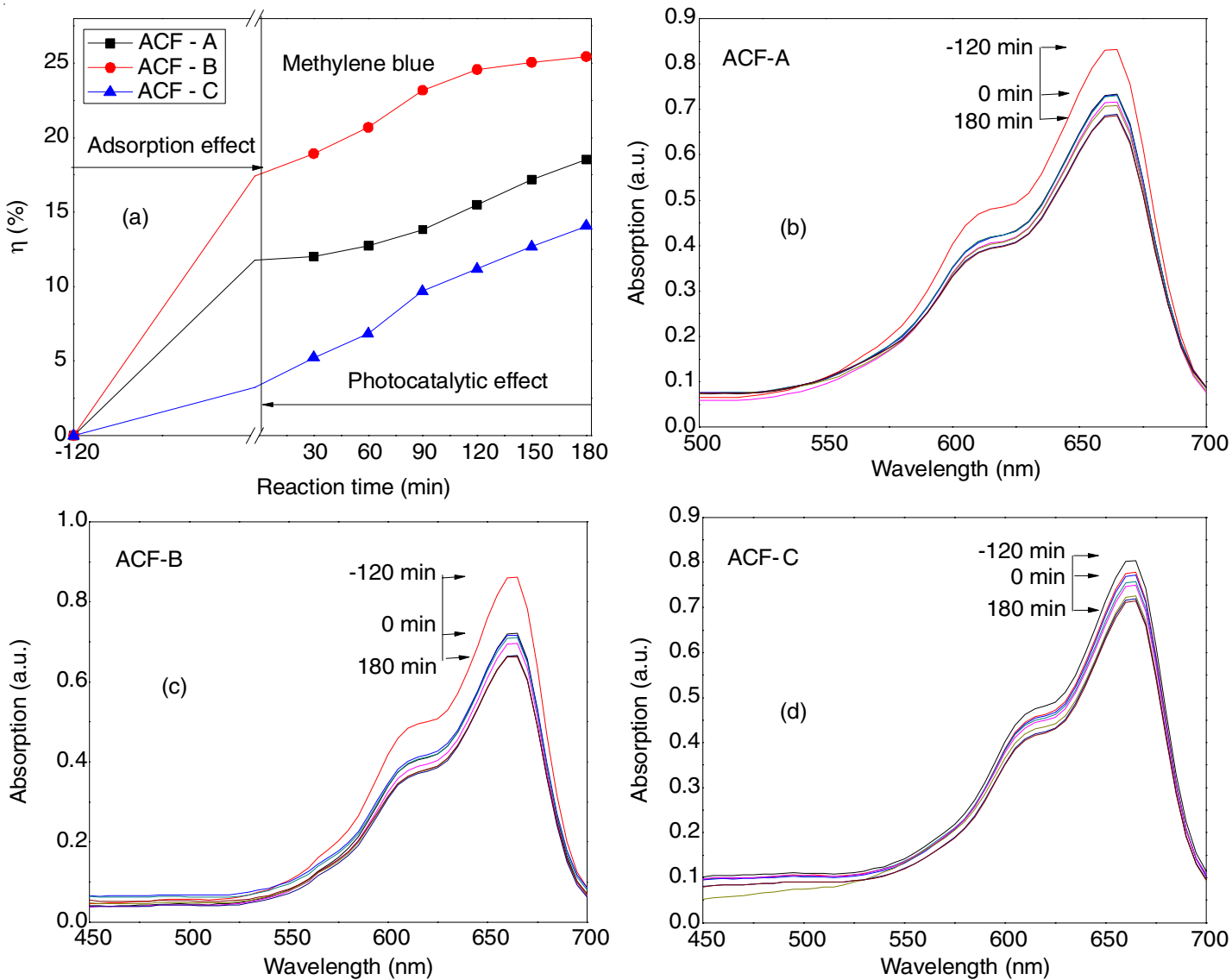

Fig. 6. Degradation of different composites with methylene blue trihydrate under visible light irradiation. The amount of composites was $0.05 \mathrm{~g}$. The experiments were carried out at $100 \mathrm{~mL}$ of $5.0 \times 10^{-5} \mathrm{~mol} / \mathrm{L} \mathrm{mol} / \mathrm{L}$ dye concentration with neutral $\mathrm{pH}$ 

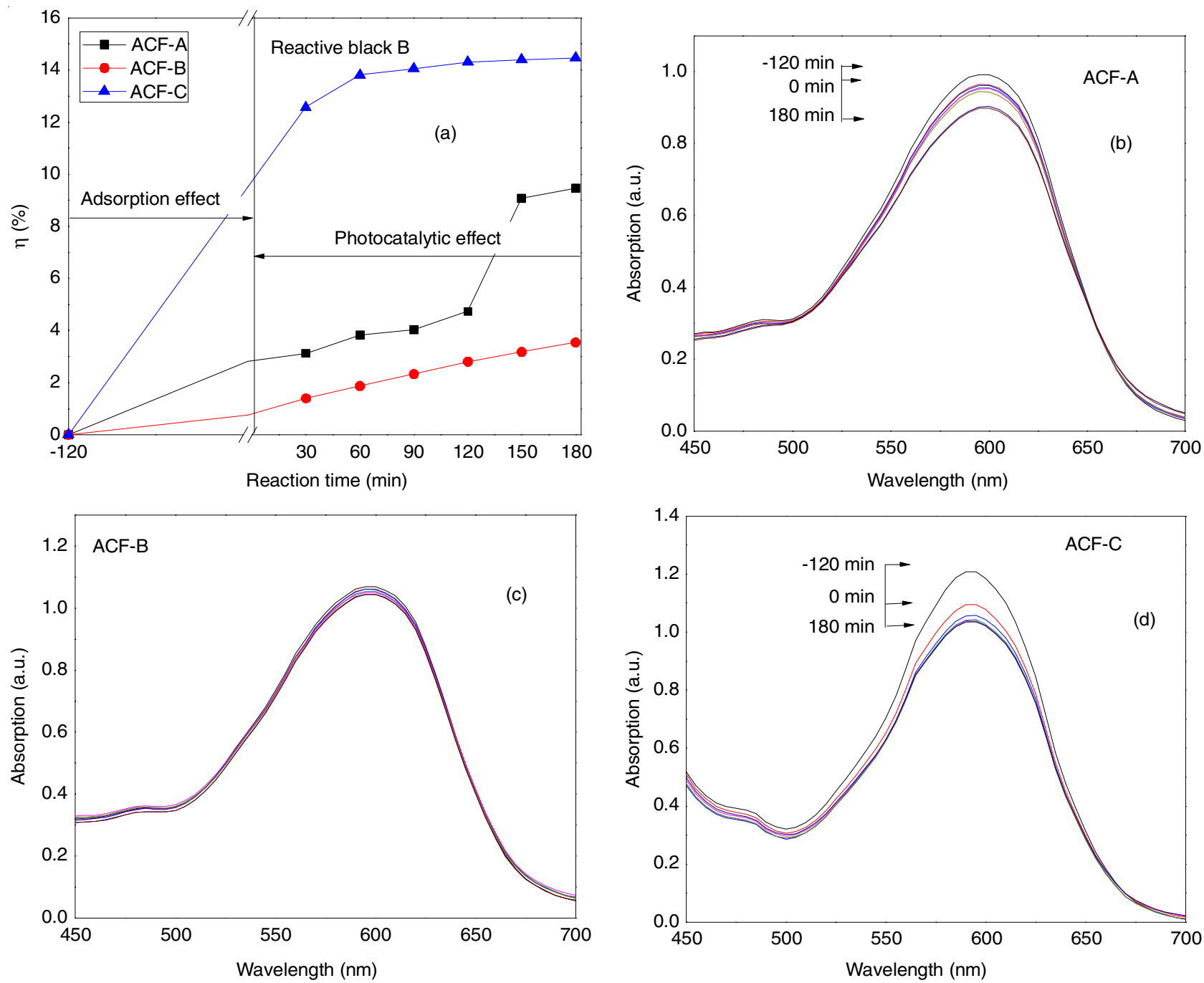

Fig. 7. Degradation of different composites with reactive black B under visible light irradiation. The amount of composites was $0.05 \mathrm{~g}$. The experiments were carried out at $100 \mathrm{~mL}$ of $5.0 \times 10^{-5} \mathrm{~mol} / \mathrm{L} \mathrm{mol} / \mathrm{L}$ dye concentration with neutral $\mathrm{pH}$

$$
-\ln \left(\mathrm{c} / \mathrm{c}_{\mathrm{o}}\right)=\mathrm{k}_{\mathrm{app}} \mathrm{t}
$$

where $\mathrm{c}$ and $\mathrm{c}_{\mathrm{o}}$ are the reactant concentration at times $\mathrm{t}=\mathrm{t}$ and $\mathrm{t}=0$, respectively, and $\mathrm{k}_{\text {app }}$ and $\mathrm{t}$ are the apparent reaction rate constant and time, respectively. According to eqn. II, a plot of $-\ln \left(\mathrm{c} / \mathrm{c}_{\mathrm{o}}\right)$ versus $\mathrm{t}$ will yield a slope of $\mathrm{k}_{\mathrm{app}}$. The results are shown in Fig. 8. The reactive black B degradation rate constant for ACF-B reached $8.0 \times 10^{-3} \mathrm{~min}^{-1}$, and the result was greater than both ACF-A and ACF-C composites. On the other hand, rhodamine $\mathrm{B}$ degradation rate constant for ACF-B obtained $6.5 \times 10^{-3} \mathrm{~min}^{-1}$, which higher than other composites. In the methylene blue case, the highest methylene blue degradation rate constant reached $7.9 \times 10^{-3} \mathrm{~min}^{-1}$ for $\mathrm{ACF}-\mathrm{C}$ composite.

It is known that the photocatalytic activity of prepared composite reflects two factors that influence the degradation rate: (a) the adsorption capacity and (b) the decomposition effect through catalysis. In the adsorption case, the great pores and have large surface area of ACF allows a greater amount of guest species over the catalysts, and the reaction will not be limited to photocatalytic surface [32]. Then, the highly enhancement of adsorption as well as the absorption rate of dyes will be occured. Under the visible light irradiation, ACF acts as the free electrons source and $\mathrm{Bi}_{2} \mathrm{O}_{3}$ particles play a role like a

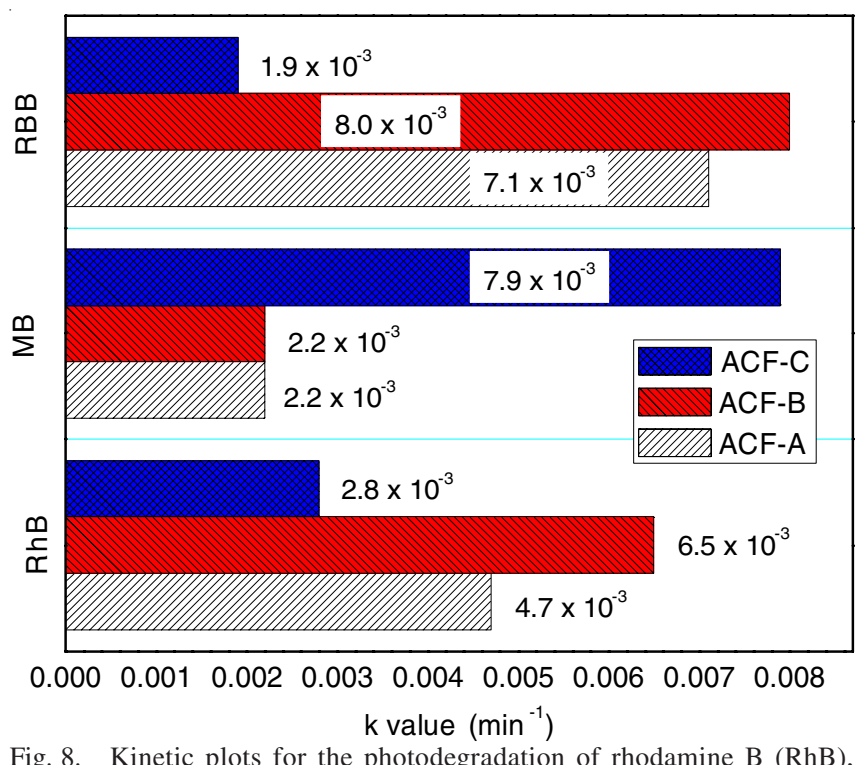

Fig. 8. Kinetic plots for the photodegradation of rhodamine $B(R h B)$, methylene blue trihydrate $(\mathrm{MB})$ and reactive black $\mathrm{B}(\mathrm{RBB})$ solution under visible light irradiation over different composites. The amount of composites was $0.05 \mathrm{~g}$. The photodegradation of the rhodamine $\mathrm{B}$, methylene blue trihydrate and reactive black B solution was carried out at $100 \mathrm{~mL}$ of $5 \times 10^{-5} \mathrm{~mol} / \mathrm{L}$ dye concentration with neutral $\mathrm{pH}$ 
bridge for the transfer of the free electrons from ACF. Besides, $\mathrm{ACF}$ can be accept the electrons produced by light irradiation. In the conduction band (CB) and valence band (VB) case, $\mathrm{Bi}_{2} \mathrm{O}_{3}$ can be also excited to produce electrons and holes under visible light irradation. The photogenerated electrons of $\mathrm{Bi}_{2} \mathrm{O}_{3}$ can switch to ACF surface to join the reduction reaction $\left(\mathrm{e}_{\mathrm{CB}}^{-}\right)$. On the other hand, the photogenerated holes of $\mathrm{Bi}_{2} \mathrm{O}_{3}$ can also switch the graphene surface to participate in oxidation reactions $\left(\mathrm{h}^{+}{ }_{\mathrm{VB}}\right)$. With this mechanism, the reduced electron-hole recombination leads to an increase in the catalytic ability. The photogenerated electron-hole shifts to the surface and interacts with substances, such as the hydroxyl group and oxygen, where the adsorption creates free radicals on the surface of the semiconductor. After that, the dye molecules can react with oxygen peroxide radicals $\mathrm{O}_{2}{ }^{--}$and hydroxyl radicals $\mathrm{OH}^{\bullet}$ to $\mathrm{CO}_{2}, \mathrm{H}_{2} \mathrm{O}$ and mineralization products (Fig. 9) [33-36]:

$$
\begin{gathered}
\mathrm{Bi}_{2} \mathrm{O}_{3}-\mathrm{ACF}+\mathrm{h} v \longrightarrow\left(\mathrm{Bi}_{2} \mathrm{O}_{3}-\mathrm{ACF}\right)\left(\mathrm{h}^{+}\right)+\left(\mathrm{Bi}_{2} \mathrm{O}_{3}-\mathrm{ACF}\right)\left(\mathrm{e}^{-}\right) \\
\left(\mathrm{Bi}_{2} \mathrm{O}_{3}-\mathrm{ACF}\right)\left(\mathrm{e}^{-}\right) \longrightarrow \mathrm{Bi}_{2} \mathrm{O}_{3}+\mathrm{ACF}\left(\mathrm{e}^{-}\right) \\
\mathrm{ACF}\left(\mathrm{e}^{-}\right)+\mathrm{O}_{2} \longrightarrow \mathrm{ACF}+\mathrm{O}_{2}^{\bullet-} \\
\left(\mathrm{Bi}_{2} \mathrm{O}_{3}-\mathrm{ACF}\right)\left(\mathrm{h}^{+}\right)+\mathrm{OH}^{-} \longrightarrow \mathrm{Bi}_{2} \mathrm{O}_{3}-\mathrm{ACF}+\mathrm{OH}^{\bullet} \\
\left(\mathrm{Bi}_{2} \mathrm{O}_{3}-\mathrm{ACF}\right)\left(\mathrm{h}^{+}\right)+\mathrm{H}_{2} \mathrm{O} \longrightarrow \mathrm{Bi}_{2} \mathrm{O}_{3}-\mathrm{ACF}+\mathrm{OH}^{\bullet}+\mathrm{H}^{+}
\end{gathered}
$$

$\mathrm{O}_{2}{ }^{--}$or $\mathrm{OH}^{\bullet}+$ organic dyes $\rightarrow \mathrm{CO}_{2}+\mathrm{H}_{2} \mathrm{O}+$ mineralized products

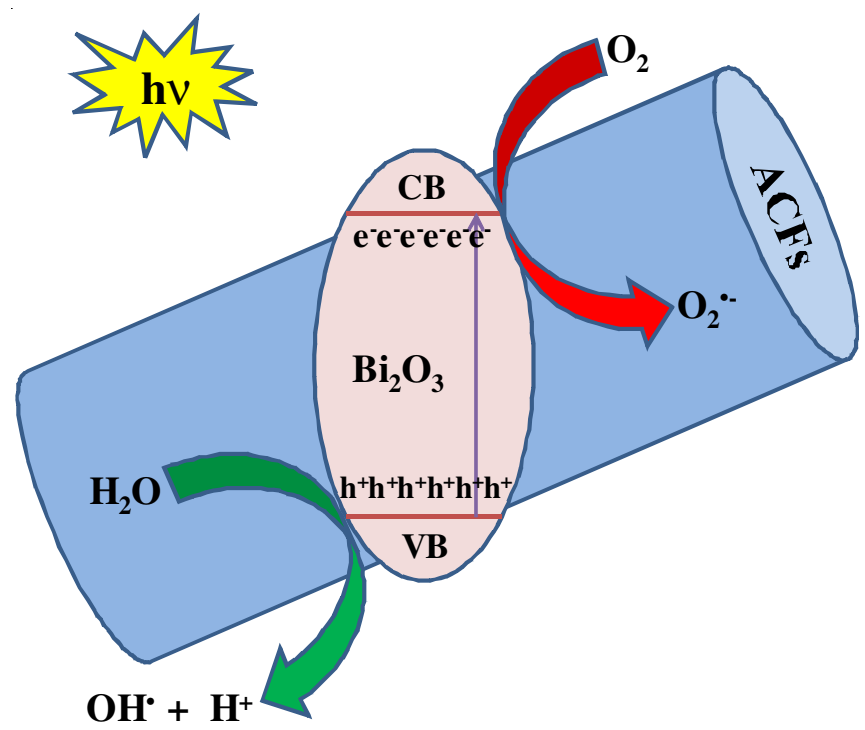

Fig. 9. Scheme of excitation and charge transfer process between $\mathrm{Bi}_{2} \mathrm{O}_{3}$ particles and ACFs

From the above results, it can seen that ACF exhibited the important role in the decolouration of organic dyes [18]. The anchorage and interaction between $\mathrm{Bi}_{2} \mathrm{O}_{3}$ particles on the ACF surface is the key role for improved the photodegradation of dyes [37].

\section{Conclusion}

A combination of activated carbon fiber $(\mathrm{ACF})$ and $\mathrm{Bi}_{2} \mathrm{O}_{3}$ particles were successfully synthesized by facile method. The XRD patterns presented the monoclinic phase of $\mathrm{Bi}_{2} \mathrm{O}_{3}$ particles. Moreover, the morphological characteristics of $\mathrm{Bi}_{2} \mathrm{O}_{3}$ particles on ACF surface were analyzed through SEM. The EDX quantitative elemental mapping indicates the presence of primary elements such as $\mathrm{C}, \mathrm{O}$, and $\mathrm{Bi}$ while the FT-IR spectrum shows the structural differences between $\mathrm{Bi}_{2} \mathrm{O}_{3}$ activated carbon fiber and activated carbon fiber through the removal of oxygen-containing groups and the appearance of a new characteristic band. The photodegradation of rhodamine $\mathrm{B}$, methylene blue and reactive black B dyes using of prepared materials was tested under visible light irradiation. The anchorage and interaction between $\mathrm{Bi}_{2} \mathrm{O}_{3}$ particles on the $\mathrm{ACF}$ surface is the key role for improved photodegradation of dyes.

\section{REFERENCES}

1. S.-M. Jin, M.-T. Tang and W.-J. Yang, J. Central South Univ. Technol.: Nat. Sci., 32, 247 (2001).

2. H.-P. Yang, Y.-N. Fan, M. Lin, B.-L. Xu and Y. Chen, Chin. J. Catal., 23, 1006 (2002)

3. Z. Jiang, L. Zhang, L. Cai and C. Xia, Electrochim. Acta, 54, 3059 (2009); https://doi.org/10.1016/j.electacta.2008.11.067.

4. S. Sarat, N. Sammes and A. Smirnova, J. Power Sources, 160, 892 (2006); https://doi.org/10.1016/j.jpowsour.2006.02.007.

5. A.A. Tomchenko, Sens. Actuators B Chem., 68, 48 (2000); https://doi.org/10.1016/S0925-4005(00)00460-3.

6. H. Oudghiri-Hassani, S. Rakass, F.T. Al Wadaani, K.J. Al-Ghamdi, A. Omer, M. Messali and M. Abboudi, J. Taibah Univ. Sci., 9, 508 (2015); https://doi.org/10.1016/j.jtusci.2015.01.009.

7. J. Cao, X. Li, H. Lin, S. Chen and X. Fu, J. Hazard. Mater, 239-340, 316 (2012);

https://doi.org/10.1016/j.jhazmat.2012.08.078.

8. C. Pan, X. Li, F. Wang and L. Wang, Ceram. Int., 34, 439 (2008); https://doi.org/10.1016/j.ceramint.2006.10.009.

9. W. Xiaohong, Q. Wei and H. Weidong, J. Mol. Catal. Chem., 261, 167 (2007); https://doi.org/10.1016/i.molcata.2006.08.016.

10. L. Madler and S.E. Pratsinis, J. Am. Ceram. Soc., 85, 1713 (2002); https://doi.org/10.1111/j.1151-2916.2002.tb00340.x.

11. H.-O. Jungk and C. Feldmann, J. Mater. Sci., 36, 297 (2001); https://doi.org/10.1023/A:1004895605613.

12. W.-M. He, Q. Zhen, Q.-Y. Pan and J.-Q. Liu, J. Funct. Mater, 34, 702 (2003).

13. L. Wei, J. Central South Univ.: Sci. Technol., 36, 175 (2005).

14. B. Zheng, Z.-G. Ren, J.-Y. Tong and J.-S. Gu, Chem. Res. Appl., 16, 411 (2004).

15. B. Zheng, A.-H. Pang and J.-S. Gu, Chem. J. Chin. Univ., 26, 628 (2005).

16. W.L. Hong, F.Q. Zhao, J.-H. Liu and D.-Y. Tian, Chinese J. Explosives Propellants, 24, 7 (2001).

17. M. Mallahi, A. Shokuhfar, M.R. Vaezi, A. Esmaeilirad and V. Mazinani, Am. J. Eng. Res., 3, 162 (2014).

18. P.F. Fu, Y. Luan and X.G. Dai, J. Mol. Catal. Chem., 221, 81 (2004); https://doi.org/10.1016/j.molcata.2004.06.018.

19. A. Fujishima and K. Honda, Nature, 238, 37 (1972); https://doi.org/10.1038/238037a0.

20. A. Fujishima, T.N. Rao and D.A. Tryk, J. Photochem. Photobiol. Photochem. Rev., 1, 1 (2000); https://doi.org/10.1016/S1389-5567(00)00002-2.

21. H.K. Son, S. Sivakumar, M.J. Rood and B.J. Kim, J. Hazard. Mater, 301, 27 (2016); https://doi.org/10.1016/j.jhazmat.2015.08.040.

22. G.B. Baur, I. Yuranov and L. Kiwi-Minsker, Catal. Today, 249, 252 (2015); https://doi.org/10.1016/j.cattod.2014.11.021.

23. Z. Shen, W. Wang, J. Jia, J. Ye, X. Feng and A. Peng, J. Hazard. Mater, 84, 107 (2001); https://doi.org/10.1016/S0304-3894(01)00201-1.

24. J. Li, Z. Yu, M. Gao and X. Cai, Water Air Soil Pollut., 97, 367 (1997); https://doi.org/10.1023/A:1026426516790.

25. S. Yao, J. Li and Z. Shi, Particuology, 8, 272 (2010); https://doi.org/10.1016/j.partic.2010.03.013.

26. M. Li, B. Lu, Q.-F. Ke, Y.-J. Guo and Y.-P. Guo, J. Hazard. Mater, 333, 88 (2017); https://doi.org/10.1016/j.jhazmat.2017.03.019.

27. J. Xia, M. Tang, C. Chen, S. Jin and Y. Chen, Trans. Nonferrous Met. Soc. China, 22, 2289 (2012); https://doi.org/10.1016/S1003-6326(11)61462-3. 
28. Z. Jiang, B. Huang, Z. Lou, Z. Wang, X. Meng, Y. Liu, X. Qin, X. Zhang and Y. Dai, Dalton Trans., 43, 8170 (2014); https://doi.org/10.1039/c4dt00483c.

29. Y.N. Wang, K.J. Deng and L.Z. Zhang, J. Phys. Chem. C, 115, 14300 (2011);

https://doi.org/10.1021/jp2042069.

30. D.C.T. Nguyen, K.Y. Cho and W.-C. Oh, RSC Advances, 7, 29284 (2017); https://doi.org/10.1039/C7RA03526H.

31. Y. Li, X. Li, J. Li and J. Yin, Water Res., 40, 1119 (2006); https://doi.org/10.1016/j.watres.2005.12.042.

32. Y. Yao, L. Wang, L. Sun, S. Zhu, Z. Huang, Y. Mao, W. Lu and W. Chen, Chem. Eng. Sci., 101, 424 (2013); https://doi.org/10.1016/j.ces.2013.06.009.
33. R. Raghav, P. Aggarwal and S. Srivastava, AIP Conf. Proc., 1724, 020078 (2016); https://doi.org/10.1063/1.4945198.

34. J.P. Espinós, J. Morales, A. Barranco, A. Caballero, J.P. Holgado and A.R. González-Elipe, Catalysts. J. Phys. Chem. B, 106, 6921 (2002); https://doi.org/10.1021/jp014618m.

35. W.-C. Oh, M. Chen, K. Cho, C. Kim, Z. Meng and L. Zhu, Chin. J. Catal., 32, 1577 (2011); https://doi.org/10.1016/S1872-2067(10)60264-1.

36. D.C.T. Nguyen, K.-Y. Cho and W.-C. Oh, Appl. Surf. Sci., 412, 252 (2017); https://doi.org/10.1016/j.apsusc.2017.03.248.

37. C.H. Ao and S.C. Lee, Appl. Catal. B, 44, 191 (2003); https://doi.org/10.1016/S0926-3373(03)00054-7. 